\title{
Occlusal characteristics in facial pain cases and controls - 12-year follow-up of the Northern Finland Birth Cohort (NFBC) 1966
}

\begin{abstract}
Objective: The purpose of this study was to investigate the occlusal characteristics in Finnish adults at 12-year follow-up based on the Northern Finland Birth Cohort 1966 (NFBC 1966).

Methods: The occlusal analyses of gypsum casts (in 2000, at 34 years of age) and digital models (in 2012, at 46 years of age) of facial pain cases $(n=52)$ and controls $(n=49)$ were performed using analysis software by two different methods: Peer Assessment Rating (PAR) Index (Method 1), and bilateral canine relationship, first molar relationship and dental midline measurements (Method 2).

Results: A tendency for higher PAR scores in right buccal occlusion was found in the facial pain cases both at the age of 34 and the age of 46 years. A significant decrease in upper anterior segment PAR score was found in the controls at the 12-year follow-up, indicating improvement in teeth alignment.

The lateral molar relationship (Method 2) showed a more mesial occlusion on the right and left in the controls compared to facial pain cases at the 34-year examination $(\mathrm{p}=0.032$, $\mathrm{p}=0.044$, respectively). At the 46-year follow-up, a more mesial occlusion on the right side was found in the controls as compared to cases $(\mathrm{p}=0.045)$.

In facial pain cases, at the 12-year follow-up left lateral occlusal relationship was significantly decreased $(\mathrm{p}=0.009)$ and occlusal asymmetry and overjet were significantly increased $(\mathrm{p}=0.052, \mathrm{p}=0.022$; respectively), while midline asymmetry was significantly decreased $(\mathrm{p}=0.045)$.
\end{abstract}


In the controls, the left canine showed a more normal occlusal relationship $(\mathrm{p}=0.003)$, cuspid asymmetry was changed $(\mathrm{p}=0.002)$, and midline asymmetry was significantly decreased $(\mathrm{p}=0.001)$.

Conclusion: During the 12-year period, occlusal asymmetry and overjet increased significantly in the facial pain cases, while occlusal relationship showed more normal characteristics in the controls.

Keywords: cohort study, NFBC 1966, occlusal characteristics, facial pain

\section{Introduction:}

Temporomandibular disorders (TMD) include pain and functional disturbances of the masticatory system [1]. The aetiology of TMD is multifactorial and the relationship between occlusion and TMD is controversial $[2,3,4,5]$.

Occlusal dimensions change throughout life. Occlusion has been suggested to be a dynamic rather than a stable part of facial structures [6,7]. Longitudinal studies have shown that overbite often increases, and especially irregularities of the upper and lower incisors are common [1]. Positive correlations between the upper intercanine width and the lower arch perimeter have been reported [8]. An inverse correlation between the upper intercanine width and the irregularity index of the upper incisors has been observed [9]. It has been noted that in the third decade of life, dental arch crowding seems to be continuing $[10,11,12]$. A retrospective longitudinal study showed greater average overbite, overjet, and degree of crowding in orthodontically untreated than in treated subjects [13]. The findings of Bishara et al. showed changes in the dimensions of the upper and lower arch and also in occlusion in both genders in middle age [14]. A 40-year follow-up-study reported increases in clinical crown height of the posterior teeth, incisor crowding and decrease in mesio-distal tooth size, mandibular intercanine width, changes 
of overbite, curve of Spee, arch length, and arch perimeter [8]. Generally, more severe changes in occlusion have been found in women than in men, but some studies have shown a larger decrease in maxillary arch length in men than in women $[7,15,16,17]$.

The Northern Finland Birth Cohort 1966 (NFBC1966) study investigates health and wellbeing in subjects born in 1966 in Northern Finland [18]. Previous reports on these cohort subjects showed differences in occlusal sagittal relationships when comparing facial pain subjects with pain-free controls, showing association between mesial canine relation and facial pain [19]. No long-term follow-up study of sagittal relationship has been performed before. The follow-up study of NFBC1966 in 2012-2013 included questionnaires, oral and medical examinations, and pantomograph dental and 3D dental models, and thus offered a possibility to evaluate occlusal changes in a longitudinal study design [20]. The aim of the study was to evaluate the occlusal characteristics in subjects with facial pain and in pain-free controls in NFBC 1966 at 12-year follow-up. The hypothesis was that changes in occlusal characteristics differ in facial pain cases and pain-free controls during the follow-up period.

\section{Material and Methods}

The NFBC 1966 is a longitudinal and epidemiologic research programme concerning subjects in an unselected population born in 1966 in Oulu and Lapland, two northern provinces in Finland (http://www.oulu.fi/nfbc/) [18,21]. The research programme is coordinated by the Department of Health Sciences, Faculty of Medicine, University of Oulu.

At first follow-up (T1), in 2000, the NFBC 1966 study, two groups of NFBC1966 subjects were formed based on facial pain report: facial pain cases $(n=162)$ included subjects who reported facial pain in previous Questionnaire I 1997-1998 ( $\mathrm{n}=5696)$ [19]. 
The question was "Have you had pain in the face during the last years?" The control group ( $n=200$ ) was composed of a random sample of subjects who had reported no facial pain. Postal Questionnaire II including the same question and question about willingness to participate the clinical stomatognathic examination was sent to these subjects $(n=362)$ in 2000. The exclusion criteria were facial pain condition different from that in 19971998, not willing to participate and/or incomplete answers. The control group was matched for gender by the proportional allocation method. There were 52 subjects in both groups attending the clinical stomatognathic examination. Alginate impressions were taken from the dentition, and occlusion was recorded in the intercuspal position (ICP) [19].

At second follow-up (T2), in 2012, the NFBC 1966 46-year follow-up study of the cohort subjects was performed. The study included questionnaires related to the subject's background information (lifestyle, health, economy, work, mental resouces etc.) and clinical oral and medical examinations [20]. In addition, Questionnaires I and II included two questions concerning TMD symptoms according to Nilsson et al [22]. The questions were "Do you have pain in your temples, temporomandibular joints, face, or jaw?" and “Do you have pain when open your mouth wide or chew?" Questionnaire III included further questions related to TMD using the modified Diagnostic Criteria for Temporomandibular Disorders (DC/TMD) diagnostic protocol i.e. "Have you had pain in areas of your face, jaws, temples, ears, or behind your ears during the prior 30 days?"[20]. Those NFBC 1966 subjects $(n=3150)$ currently living in the Oulu region were invited to clinical stomatognathic examination. Altogether 1962 subjects (1050 women, 912 men) attended the examination [20]. From the original case group 45 and from the control group 49 subjects attended this follow-up study.

Digital 3D models (STL file format) were taken of the dentition of all subjects using an 
intraoral scanner. The gypsum casts from the 34-year follow-up study [19] were digitized by using a three-dimensional (3D) surface laser scanner [23].

The occlusal analyses for this study were performed on these digital models in both groups (A, B) and both time points $(\mathrm{T} 1, \mathrm{~T} 2)$ by using analysis software [23]. Twelve gypsum casts were not available, and a several subjects had lost their reference teeth due to extraction during the 12-year follow-up period so that measurements could not be performed. Finally, 42 cases and 44 controls were included in the present study. Number of subjects varied here between different measurements because of some missing index teeth (canines and/or first molars).

The occlusal analyses were performed by two different methods: 1) Peer Assessment Rating (PAR) Index (cases $n=38$, controls $n=40$ ) by Richmond, et al. [24], and 2) the bilateral canine and first molar relationship and dental midline measurements (cases $n=30-36$, controls $n=32-39$ ) by a method presented by Pirttiniemi, et al. [23,25].

The distance of the mesial contact point of the lower first molar to that of the upper first molar was measured on the right and the left sides.

\section{PAR assessment (Method 1)}

The PAR index has been developed to assess the severity of malocclusion [24]. The PAR index consists of five components: anterior segment (crowding, spacing and impacted teeth), buccal segments (sagittal, vertical and transversal relationships), overjet, overbite, and midline. The individual scores of the components were weighted according to British weightings and summed to the weighted PAR score [24]. Higher scores indicated increased levels of irregularity and malocclusion. In cases with an individual missing tooth, a space of more than $4 \mathrm{~mm}$ was not recorded. One examiner (A-SS), trained and calibrated for the use of the PAR index, scored the digital study models. The examiner 
was not aware of the case-control status of the subjects. Digital 3D analysis has previously been shown to be a valid and reliable method for occlusal measurements (Kiviahde et al. 2017, [23]). Occlusal plane was determined from the mesiobuccal cusps of the first molars to the tip of the central incisor separately for the maxilla and mandible.

\section{Lateral occlusal relationship (Method 2)}

The method presented by Pirttiniemi, et al. [23,25] measures differences in occlusal sagittal relationships and in the dental midline. The digital 3D models were measured in relation to the occlusal plane (figure 1) [23]. The canine relationship measurements were performed defining the most distal points of the upper and lower canines on the right (R3) and left (L3) side. The first molar relationship measurements were done by choosing the most mesial points of the upper and lower first molars on the right (R6) and left (L6) side. The bilateral canine and first molar relationship are the difference between L3-R3 and L6-R6.

Midline asymmetry measurements were performed in the frontal view by defining two points: one on the upper incisal midline and the other on the lower incisal midline. For overjet and overbite measurements, the sagittal plane was defined as running through the mesio-incisal edge of the upper right central incisor. The measuring area was magnified in the sagittal view and two points were defined. A positive value indicates anterior location of the lower canine and posterior location of the lower first molar; the lower incisor midline was to the right, in relation to the upper [23].

\section{Statistical Analyses}

Statistical analyses were performed using IBM SPSS Statistics (version 24.0). $P$ values less than .05 were considered to be statistically significant. The independent samples ttest or Mann-Whitney U test were used to compare the measurements of the components 
and the weighted total Peer Assessment Rating (PAR) as well as measurements of occlusal variables between the facial pain and control groups at the age of 34 and 46 . Components of the PAR index and occlusal variables measured between the two age points were compared with paired samples t-test or Wilcoxon signed rank test in facial pain and control groups.

The Ethical Committee of Northern Ostrobothnia Hospital District approved the study (17.5.2006 and 74/2011).

\section{Results}

The weighted PAR total and item scores are presented in Table 1, separately for upper and lower anterior segments, and right and left buccal segments. In the controls, a significant decrease in upper anterior segment score was found during the 12-year followup, indicating improvement in teeth alignment $(\mathrm{p}=0.034)$. The facial pain cases had a tendency, but not a significant one, for higher PAR scores in right buccal occlusion compared to the controls at the age of 34 (T1) and the age of 46 (T2) (p=0.052 and $\mathrm{p}=0.069$, respectively).

The occlusal variables (Method 2.) of the facial pain cases and controls are presented in Table 2. At the 34-year examination (T1), the distance between the lower right first molar in relation to the upper right first molar (R6) was significantly larger in the facial pain cases compared to the controls ( $\mathrm{p}=0.032$ ). The distance between the left first molar (L6) in relation to the upper left first molar was also larger in the facial pain cases than in the controls $(\mathrm{p}=0.044)$, showing a more mesial occlusion in the controls.

At the 46-year follow-up (T2), the distance between the right first molar in relation to the upper right first molar (R6) was significantly larger in the facial pain cases compared to 
the controls $(\mathrm{p}=0.045)$, showing a more mesial occlusion in the controls on the right side (Table 2).

At the 12-year follow-up (T1-T2), left lateral occlusal relationship (L6) was significantly decreased in the facial pain cases $(\mathrm{p}=0.009)$. Occlusal asymmetry (L3-R3) and overjet were significantly increased $(\mathrm{p}=0.052, \mathrm{p}=0.022$; respectively) while midline asymmetry was significantly decreased $(\mathrm{p}=0.045)$.

In the controls, (T1-T2) the left canine (L3) showed a more normal occlusal relationship $(\mathrm{p}=0.003)$ at the 12-year follow-up. The cuspid asymmetry (L3-R3) was changed $(\mathrm{p}=0.002)$ and the midline asymmetry was significantly decreased $(\mathrm{p}=0.001)$.

\section{Discussion}

The results of the study indicate that the occlusal characteristics had changed during the 12-year follow-up in both the facial pain cases and the controls, the changes being different between the groups. As compared to cases, the occlusion in the controls was noted to be more stable in the posterior teeth, and the occlusal relationship of the anterior teeth was closer to the ideal occlusion. Additionally, this study showed a tendency for improvement of occlusion in the controls, as measured by PAR index.

In the present study, significant differences were found between the groups in 12-year follow-up. A statistically significant difference was found in the left molar relationship, which means a more distal occlusal relationship in the facial pain cases. The canine relationship and the midline showed significant changes in the controls, and to a less degree, in facial pain cases, toward a more normal occlusal relationship.

The significant changes on the left side support previous findings showing more prominent left-sided protrusiveness of the mandible compared to the right side [26,27]. 
Wieczorek et al. found that distribution of occlusal contacts in relation to the midline was not equal and dominated on the left side in asymptomatic young adults [28]. It has also been noted that the dental arch morphology affects the masticatory muscle activities [29]. Especially occlusal surface morphology of premolars has been suspected to influence on occlusion time [30]. On the other hand, according to Martinez-Gomis et al. [27], nearly $88 \%$ of the subjects were observed to have a preferred chewing side on the right or had no preferred chewing side. The same study showed that cementum thickness was markedly greater on the distal surfaces of teeth compared to the mesial surfaces, and that this may be due to functional stimulation from mesial drift over time [31]. Furthermore, in their follow-up study (from the age 7 to 32 years) Heikinheimo et al. showed that although all increases in dental arch width dimensions occurred before 15 years of age, there was considerable variability [17]. Differences between growth changes in the distal, mesial, and gingival intermolar widths show that the first molars rotate mesio-lingually and that the maxillary first molars become more upright during growth [32]. Tsiopas et al. showed, in adults aged from 20 years to 60 years, a significant increase in mandibular teeth irregularity and a decrease in the maxillary and mandibular intercanine width [33]. Bondevik noted in a 11-year follow-up study a decrease in arch depth, intercuspid width and anterior space in both arches in both genders [34].

A previous study using PAR measurements found statistically significant differences in lower anterior segments and overbite between facial pain cases and controls [19]. In the present study, sagittal occlusal relationships measured according to Pirttiniemi et al. (Method 2) showed good sensitivity in detecting occlusal discrepancies when compared with the PAR index (Method 1). Here, the PAR measurements were done by using 3D measuring software, which may have had an influence on the findings. The results show that digitally performed inter-arch measurements have excellent accuracy and reliability 
as shown earlier [23]. The strength of the research was the long, 12-year follow-up, based on the NFBC1966 cohort study using accurate modern digital methods. Loss of material due to the long follow-up limits the reliability of the results.

\section{Conclusion}

During the 12-year period, occlusal asymmetry and overjet increased significantly in the facial pain cases while occlusal relationship showed more normal characteristics in the controls.

\section{Acknowledgments}

The authors thank the late professor Paula Rantakallio (launch of NFBC 1966), the NFBC project centre, and the participants in the 46y study. NFBC 1966 received financial support from University of Oulu Grant No. 24000692, Oulu University Hospital Grant No. 24301140, and ERDF European Regional Development Fund Grant No. 539/2010 A31592. The authors report no conflicts of interest. 


\section{References}

[1] Okeson JP. Management of temporomandibular disorders and occlusion. 7th ed. St Louis: Elsevier; 2013

[2] Durham J, Newton-John TR, Zakrzewska JM. Temporomandibular disorders BMJ. 2015;12:350,h1154.

[3] Huttunen J, Qvintus V, Suominen AL, et al. Role of psychosocial factors on treatment outcome of temporomandibular disorders. Acta Odontol Scand. 2019;77:119-125.

[4] De Boever JA. Functional disturbances of temporomandibular joints. Oral Sci Rev. 1973;2:100-117.

[5] Jussila P, Krooks L, Näpänkangas R, et al. The role of occlusion in temporomandibular disorders (TMD) in the Northern Finland Birth Cohort (NFBC) 1966. Cranio, 2019;37:231-237.

[6] Thilander B. Dentoalveolar development in subjects with normal occlusion. A longitudinal study between the ages of 5 and 31 years. Eur J Orthod. 2009;31:109-120.

[7] Pirttiniemi PM, Oikarinen KS, Raustia AM. The effect of removal of all third molars on the dental arches in the third decade of life. Cranio. 1994;12:23-27.

[8] Tibana RH, Palagi LM, Miguel JA. Changes in Dental Arch Measurements of Young Adults with Normal Occlusion-A Longitudinal Study. Angle Orthod. 2004;74:618-623. [9] Massaro C, Miranda F, Janson G et al. Maturational changes of the normal occlusion: A 40-year follow-up. Am J Orthod Dentofacial Orthop. 2018;154:188-200.

[10] Mauad BA, Silva RC, Aragón ML, et al. Changes in lower dental arch dimensions and tooth alignment in young adults without orthodontic treatment. Dental Press J Orthod. 2015;20:64-68.

[11] Tsiopas N, Nilner M, Bondemark L et al. A 40 years follow-up of dental arch dimensions and incisor irregularity in adults. Eur J Orthod. 2013;35:230-235.

[12] Akgül AA, Toygar TU. Natural craniofacial changes in the third decade of life: a longitudinal study. Am J Orthod Dentofacial Orthop. 2002;122:512-522.

[13] Driscoll-Gilliland J, Buschang PH, Behrents RG. An evaluation of growth and stability in untreated and treated subjects. Am J Orthod Dentofacial Orthop. 2001;120:588-597.

[14] Bishara SE, Treder JE, Damon P, et al. Changes in the dental arches and dentition between 25 and 45 years of age. Angle Orthod. 1996;66:417-422.

[15] Sinclair PM, Little RM. Maturation of untreated normal occlusions. Am J Orthod. 1983;83:114-123. 
[16] Bishara SE, Jakobsen JR, Treder J, et al. Arch length changes from 6 weeks to 45 years. Angle Orthod. 1998;68:69-74.

[17] Heikinheimo K, Nyström M, Heikinheimo T, et al. Dental arch width, overbite, and overjet in a Finnish population with normal occlusion between the ages of 7 and 32 years. Eur J Orthod. 2012;34:418-426.

[18] Rantakallio P. The longitudinal study of the northern Finland birth cohort of 1966. Paediatr Perinat Epidemiol. 1988;2:59-88.

[19] Sipilä K, Ensio K, Hanhela H, et al. Occlusal characteristics in subjects with facial pain compared to a pain-free control group. Cranio. 2006;24:245-251.

[20] Jussila P, Kiviahde H, Näpänkangas R, et al. Prevalence of Temporomandibular Disorders in the Northern Finland Birth Cohort 1966. J Oral Facial Pain Headache. 2017;31:159-164.

[21] Sorri M, Järvelin MR. Well-being and health. Background to the northern Finland 1966 birth cohort research. Int J Circumpolar Health. 1998;57:82-83.

[22] Nilsson IM, List T, Drangsholt M. The reliability and validity of self-reported temporomandibular disorder pain in adolescents. J Orofac Pain. 2006;20:138-44.

[23] Kiviahde H, Bukovac L, Jussila P, Pesonen P, Sipilä K, Raustia A, Pirttiniemi P. Inter-arch digital model vs. manual cast measurements: Accuracy and reliability.

Cranio. 2017;28:1-6.

[24] Richmond S, Shaw WC, O'Brien KD, et al. The development of the PAR Index (Peer Assessment Rating): reliability and validity. Eur J Orthod,1992;14:125-139.

[25] Pirttiniemi P, Raustia A, Kantomaa T, et al. Relationships of bicondylar position to occlusal asymmetry. Eur J Orthod. 1991;13:441-445.

[26] Melnik AK. A cephalometric study of mandibular asymmetry in a longitudinally followed sample of growing children. Am J Orthod Dentofacial Orthop. 1992;101:355366.

[27] Martinez-Gomis J, Lujan-Climent M, Palau S, et al. Relationship between chewing side preference and handedness and lateral asymmetry of peripheral factors. Arch Oral Biol. 2009;54:101-107.

[28] Wieczorek A, Loster JE, Loster BW, et al. Distribution of occlusal contacts in asymptomatic young adults. J Stoma. 2015; 68:681-689.

[29] Sierpinska T, Jacunski P, Kuc J, et al. Effect of the dental arches' morphology on the masticatory muscles' activities in normal occlusion young adults. Cranio, 2015;33:134-141. 
[30] Sierpinska T, Kropiwnicka A, Kuc J, et al. The influence of occlusal morphology on occlusion time. Cranio, 2017;35:101-109.

[31] Dastmalchi R, Polson A, Bouwsma O, Proskin H, et al. Cementum thickness and mesial drift. Clin Periodontol. 1990;17:709-713.

[32] Kirveskari P. The role of occlusal adjustment in the management of temporomandibular disorders, Oral Surg Oral Med Oral Pathol Oral Radiol Endod. 1997;83:87-90

[32] Tsiopas N. Nilner M. Bondemark L, et al. A 40 years follow-up of dental arch dimensions and incisor irregularity in adults. Eur J Orthod. 2013;35:230-235.

[33] Bondevik O. A longitudinal study of dental arches and occlusal changes in adults from 22 to 33, and 33 to 43 years of age. J Orofac Orthop. 2015;76:79-89. 


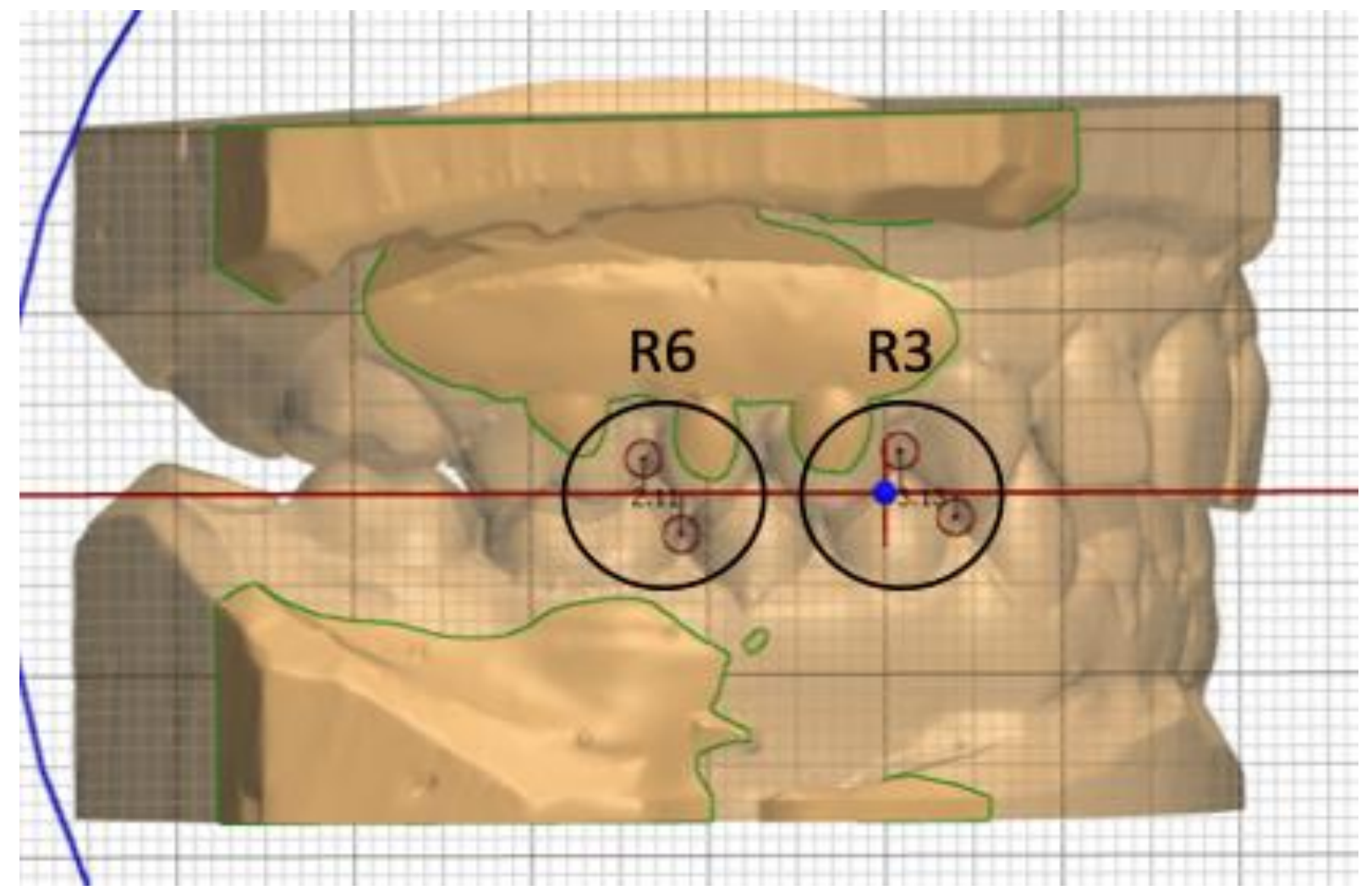

Figure 1. Measurements of the bilateral canine and bilateral first molar relationship in the sagittal view.

Bilateral canine (R3) relationship measurements were performed by defining the most distal points of the upper and lower canines, and first molar (R6) relationship measurements were done by defining the most mesial points projected on occlusal line, using the method described by Pirttiniemi et al. [7]. 
Table 1. Mean values and standard deviations of the components and the weighted total Peer Assessment Rating (PAR) Index in the facial pain cases and in the controls at the age of 34 (T1), at the age of 46 (T2) and the changes during 12-year follow-up between T1-T2.

\begin{tabular}{|c|c|c|c|c|c|c|c|c|c|c|c|c|c|c|c|c|}
\hline & \multicolumn{5}{|l|}{ T1 } & \multicolumn{5}{|l|}{$\mathbf{T 2}$} & \multicolumn{6}{|c|}{ T2-T1 } \\
\hline & \multicolumn{2}{|c|}{$\begin{array}{c}\text { Facial pain } \\
(n=38)\end{array}$} & \multicolumn{3}{|c|}{$\begin{array}{l}\text { Control } \\
(n=40)\end{array}$} & \multicolumn{2}{|c|}{$\begin{array}{c}\text { Facial pain } \\
\quad(n=38)\end{array}$} & \multicolumn{3}{|c|}{$\begin{array}{l}\text { Control } \\
(n=40)\end{array}$} & \multicolumn{3}{|c|}{$\begin{array}{c}\text { Facial pain } \\
\quad(\mathrm{n}=38)\end{array}$} & \multicolumn{3}{|c|}{$\begin{array}{l}\text { Control } \\
(n=40)\end{array}$} \\
\hline & Mean & SD & Mean & SD & $P$ & Mean & SD & Mean & $\mathrm{SD}$ & $P$ & Mean & SD & $P$ & Mean & SD & $P$ \\
\hline $\begin{array}{c}\text { Upper anterior } \\
\text { segment }\end{array}$ & 3.32 & 2.28 & 2.75 & 2.22 & $0.270^{\mathrm{a}}$ & 3.03 & 2.21 & 2.25 & 1.88 & $0.100^{\mathrm{a}}$ & -0.29 & 2.14 & $0.410^{\mathrm{c}}$ & -0.50 & 1.43 & $0.034 * \mathrm{~d}$ \\
\hline $\begin{array}{c}\text { Lower anterior } \\
\text { segment }\end{array}$ & 2.84 & 2.10 & 2.25 & 2.07 & $0.214^{\mathrm{a}}$ & 2.60 & 2.20 & 2.08 & 1.86 & $0.254^{\mathrm{a}}$ & -0.24 & 1.60 & $\begin{array}{c}0.368 \\
\mathrm{c}\end{array}$ & -0.18 & 1.59 & $0.340^{\mathrm{d}}$ \\
\hline Right buccal occlusion & 1.87 & 1.47 & 1.28 & 1.15 & $0.052^{\mathrm{a}}$ & 1.92 & 1.15 & 1.45 & 1.10 & $0.069^{\mathrm{a}}$ & 0.05 & 1.20 & $0.644^{\mathrm{d}}$ & 0.18 & 0.90 & $0.242^{\mathrm{d}}$ \\
\hline Left buccal occlusion & 1.32 & 1.45 & 1.60 & 1.35 & $0.301^{\mathrm{b}}$ & 1.45 & 1.31 & 1.50 & 1.36 & $0.880^{\mathrm{b}}$ & 0.13 & 0.88 & $0.375^{\mathrm{d}}$ & -0.10 & 1.15 & $0.427^{\mathrm{d}}$ \\
\hline Overjet & 1.00 & 1.32 & 1.08 & 1.16 & $0.593^{\mathrm{b}}$ & 1.18 & 1.18 & 1.05 & 1.22 & $0.512^{b}$ & 0.18 & 1.43 & $0.151^{\mathrm{d}}$ & -0.03 & 0.83 & $0.740^{d}$ \\
\hline Overbite & 0.79 & 0.84 & 0.80 & 0.85 & $0.996^{\mathrm{b}}$ & 0.71 & 0.80 & 0.75 & 0.74 & $0.680^{b}$ & -0.08 & 0.91 & $0.791^{\mathrm{d}}$ & -0.05 & 0.67 & $0.644^{\mathrm{d}}$ \\
\hline Centerline & 0.37 & 0.54 & 0.48 & 0.68 & $0.606^{b}$ & 0.29 & 0.52 & 0.50 & 0.64 & $0.120^{\mathrm{b}}$ & -0.08 & 0.49 & $0.317^{\mathrm{d}}$ & 0.03 & 0.58 & $0.782^{d}$ \\
\hline PAR weighted total & 18.71 & 11.65 & 17.88 & 9.68 & $0.732^{a}$ & 18.74 & 11.06 & 17.18 & 9.52 & $0.507^{\mathrm{a}}$ & 0.03 & 10.62 & $0.988^{\mathrm{c}}$ & -0.70 & 7.26 & $0.545^{\mathrm{c}}$ \\
\hline
\end{tabular}

$* P<0.05,{ }^{\mathrm{a}}$ Independent sample's t-test, ${ }^{\mathrm{b}}$ Mann-Whitney U test, ${ }^{\mathrm{c}}$ Paired samples t-test, ${ }^{\mathrm{d}}$ Wilcoxon signed rank test 
Table 2. Occlusal variables in the facial pain cases and in the controls at the age of 34 (T1) and at the age of 46 (T2) and the changes during 12 -year follow-up between T1-T2 using a method measuring the bilateral canine and first molar relationship, overjet, overbite and occlusal asymmetry (midline and L3-R3) from digital 3D models.

\begin{tabular}{|c|c|c|c|c|c|c|c|c|c|c|c|c|c|c|c|c|c|c|c|c|c|c|}
\hline & \multicolumn{7}{|l|}{ T1 } & \multicolumn{7}{|l|}{$\mathbf{T 2}$} & \multicolumn{8}{|c|}{ T1-T2 } \\
\hline & \multicolumn{3}{|c|}{ Facial pain } & \multicolumn{3}{|c|}{ Control } & \multirow[b]{2}{*}{$\mathrm{P}$} & \multicolumn{3}{|c|}{ Facial pain } & \multicolumn{3}{|c|}{ Control } & \multirow[b]{2}{*}{$\mathrm{P}$} & \multicolumn{4}{|c|}{ Facial pain } & \multicolumn{4}{|c|}{ Control } \\
\hline & Mean & SD & $n$ & Mean & SD & $n$ & & Mean & SD & $n$ & Mean & SD & $n$ & & Mean & SD & $n$ & $\mathrm{P}$ & Mean & SD & $n$ & $\mathrm{P}$ \\
\hline R3 & 1.86 & 2.31 & 36 & 1.17 & 2.32 & 39 & $0.205^{\mathrm{a}}$ & 1.78 & 2.24 & 36 & 1.03 & 2.47 & 39 & $0.173^{\mathrm{a}}$ & -0.08 & 0,68 & 36 & $0.503^{c}$ & -0.14 & 0.72 & 39 & $0.227^{c}$ \\
\hline R6 & 1.60 & 1.93 & 33 & 0.53 & 2.09 & 36 & $\begin{array}{c}0.032^{\mathrm{a}} \\
*\end{array}$ & 1.61 & 1.82 & 33 & 0.63 & 2.16 & 36 & $\begin{array}{l}0.045^{\mathrm{a}} \\
*\end{array}$ & 0.02 & 0.78 & 33 & $0.893^{c}$ & 0.10 & 0.65 & 36 & $0.349^{c}$ \\
\hline L3 & 1.53 & 2.78 & 36 & 0.86 & 2.44 & 39 & $0.277^{\mathrm{a}}$ & 2.24 & 2.61 & 36 & 1.87 & 2.64 & 39 & $0.545^{\mathrm{a}}$ & 0.72 & 2.36 & 36 & $0.077^{c}$ & 1.01 & 2.01 & 39 & $0.003^{c} *$ \\
\hline L6 & 2.17 & 1.95 & 33 & 1.11 & 2.22 & 33 & $\begin{array}{l}0.044^{\mathrm{a}} \\
*\end{array}$ & 1.77 & 1.71 & 33 & 1.26 & 2.12 & 33 & $0.289^{a}$ & -0.40 & 0.83 & 33 & $\begin{array}{l}0.009^{c} \\
*\end{array}$ & 0.15 & 0.73 & 33 & $0.235^{\mathrm{c}}$ \\
\hline L3-R3 & -0.33 & 2.52 & 36 & -0.31 & 2.47 & 39 & $0.967^{\mathrm{a}}$ & 0.46 & 3.22 & 36 & 0.84 & 2.74 & 39 & $0.582^{a}$ & 0.79 & 2.19 & 36 & $\begin{array}{l}0.052^{\mathrm{d}} \\
*\end{array}$ & 1.15 & 2.14 & 39 & $0.002^{d} *$ \\
\hline L6-R6 & 0.55 & 2.43 & 30 & 0.57 & 2.14 & 32 & $0.976^{\mathrm{a}}$ & 0.29 & 2.26 & 30 & 0.67 & 2.23 & 32 & $0.506^{\mathrm{a}}$ & -0.26 & 1.17 & 30 & $0.233^{c}$ & 0.10 & 0.81 & 32 & $0.479^{c}$ \\
\hline midline & -0.29 & 1.76 & 36 & -0.38 & 1.34 & 39 & $0.818^{\mathrm{a}}$ & 0.10 & 1.08 & 36 & 0.16 & 1.64 & 39 & $0.867^{\mathrm{a}}$ & 0.40 & 1.41 & 36 & $0.045^{\mathrm{d}}$ & 0.53 & 0.92 & 39 & $0.001^{\mathrm{d} *}$ \\
\hline overjet & 3.16 & 2.51 & 36 & 3.57 & 2.40 & 39 & $0.473^{\mathrm{a}}$ & 3.52 & 2.43 & 36 & 3.63 & 2.47 & 39 & $0.847^{\mathrm{a}}$ & 0.36 & 0.91 & 36 & $\begin{array}{l}0.022^{\mathrm{c}} \\
*\end{array}$ & 0.06 & 1.19 & 39 & $0.746^{c}$ \\
\hline overbite & 2.44 & 1.66 & 36 & 2.78 & 1.42 & 39 & $0.342^{a}$ & 2.51 & 1.60 & 36 & 2.79 & 1.68 & 39 & $0.455^{\mathrm{a}}$ & 0.71 & 0.80 & 36 & $0.598^{c}$ & 0.02 & 0.89 & 39 & $0.910^{c}$ \\
\hline
\end{tabular}

The distance $(\mathrm{mm})$ was measured on digital 3D models in relation to the occlusal plane. $R 3=d d 13 / 43, L 3=23 / 33, R 6=16 / 46, L 6=26 / 36$.

${ }^{*} P<0.05,{ }^{\mathrm{a}}$ Independent sample's t-test, ${ }^{\mathrm{c}}$ Paired samples t-test, ${ }^{\mathrm{d}}$ Wilcoxon signed rank test 